\title{
Molecular Medicine and Clinical Epidemiology: New Era, New Choices
}

$\mathrm{W}$ hat areas should new researchers in developing countries choose in order to give relevant contributions to medical knowledge?

Obviously the answer involves many different subjects. It seems to us that presently molecular medicine is very attractive. On the other hand, the applications of discoveries in molecular medicine and new therapeutic approaches require good clinical investigation methods, and especially researchers trained as Clinical Trialists or Clinical Epidemiologists. They are supposed to design clinical trials, to consider the statistical power, conduct research properly, etc.

When treatment results are moderate and the prevalence of events is rare, higher numbers of patients are needed in order to assess the new proposed treatment. Unfortunately for the people and fortunately for the researchers, developing countries have a large number of complications as compared to the same diseases in developed countries due to insufficient prevention measures and insufficient early treatment. So, from this point of view, research conducted in the poorer countries may have a higher statistical power to detect treatment differences when studying a lower number of cases, at low costs as compared to the same research in the developed countries. Indeed, some researchers in developed countries consider countries like Brazil a paradise for conducting research as long as there is an association with researchers trained in clinical

* MD, PhD, MSc, "Livre Docente" of Internal Medicine Escola Paulista de Medicina. São Paulo Medical Journal Editor. epidemiology. The same may be stated about the evaluation of new predictive diagnostic tests, which will certainly emerge from molecular medicine advances.

So young physicians who have finished a residence program could be trained in Clinical Epidemiology, and that could open the fields of clinical research and academic careers for them.

There is no doubt that in the near future any medical doctor in any specialty will need the knowledge of clinical epidemiology to improve their critical appraisal skills, and consequently, practice. Possibilities of giving relevant professional contribution in developing countries would be closer for medical doctors trained in Clinical Epidemiology who are interested in an academic career. In Brazil dozens of schools of medicine are expected to commit themselves to evidence-based medicine and hire these faculty members trained in Clinical Epidemiology in order to improve their competitive edge in attaining research grants. Also, the private health insurance groups and government policy-makers need to reduce costs; the methodology of critical appraisal of medical information, and cost/benefit analysis are excellent tools to get more of each dollar, particularly in the developing countries, where the resources are scarce.

So, considering the universe of medical specialties, it seems to us being valid suggesting to the MD newcomers to consider Clinical Epidemiology as an interesting area to learn and succeed professionally, thus improving the health system of their countries $(2,3,4,5,6)$.

The above statements may raise old polemics between classical epidemiologists and clinical epidemiologists (1).

However, our experience during the last decade is that these two types of professionals may work together positively in benefit of individuals and of the community. 


\section{REFERENCES}

1. GOLDBAUM, M. The possibilities and limits of clinical epidemiology. São Paulo Medical Journal / RPM. Special abstract supplement 113(2): 55, 1995.

2. NOBRE, M.R.C. Clinical Epidemiology - bridging the gap between the clinical practice and the medical research. São Paulo Medical Journal / RPM. Supplement 113(2):1, 1995.

3. RODRIGUES, L.C. Collaboration with Brazilian academics working outside Brazil. São Paulo Medical Journal / RPM Special Abstract Supplement 113(2): 9, 1995.
4. FLETCHER, R.H. Screening for colorectal cancer. São Paulo Medical Journal / RPM. Special Abstract Supplement 113(2), 1995.

5. FERRAZ, M.B. The importance of health economics in a world of proportionally increasing scarce resources. São Paulo Medical Journal / RPM. Special Abstract Supplement 113(2): 54, 1995.

6. FLETCHER, W.S. Screening for breast cancer. São Paulo Medical Journal / RPM. Special Abstract Supplement 113(2): 39, 1995. 